\title{
Androgen and estrogen concentrating neurons in chemosensory pathways of the male Syrian hamster brain
}

\author{
R.I. Wood, R.K. Brabec, J.M. Swann * and S.W. Newman \\ Reproductice Sciences Program, Department of Anatomy and Cell Biology, Unitersity of Michigan, Ann Arbor, MI 48109-(i616 (USA)
}

(Accepted 16 June 1992)

Key words: Androgen receptor; Estrogen receptor; Sexual behavior; Amygdala; Autoradiography; Limbic system

\begin{abstract}
The medial preoptic area (MPOA), bed nucleus of the stria terminalis (BNST), and medial amygdaloid nucleus (Me) are essential for male sevual behavior in the Syrian hamster. These nuclei received chemosensory stimuli and gonadal steroid signals, both of which are required for mating behavior. The objective of this study was to compare the distribution of androgen- and estrogen-concentrating neurons in MPOA, BNST, and Me in the adult male hamster using steroid autoradiography for estradiol (E2), testosterone (T) and dihydrotestosterone (DHT). Adult males $(n=4$ per group) received two i.p. injections of tritiated steroid 4-7 days after castration. Six- $\mu \mathrm{m}$ frozen sections through the brain were mounted onto emulsion-coated slides, and exposed for 11-16 months. In MPOA, BNST, and Me, neurons were more abundant and heavily labelled after $\left[{ }^{3} \mathrm{H}\right] \mathrm{E} 2$ treatment than after either $\left[{ }^{3} \mathrm{H}\right] \mathrm{T}$ or $\left[{ }^{3} \mathrm{H}\right] \mathrm{DHT}$. Tritiated estrad: 1 - and DHT-labeled cells were found throughout the rostrocaudal extent of Me, with a high concentration in posterodorsal Me. Tritiated testosterone treatment labelled cells largely within posterodorsal Me. In MPOA, the majority of F:2-, T-, and DHT-labelled neurons were in the medial preoptic nucleus (MPN) and the preoptic continuation of the posteromedial bed nucleus of the stria terminalis (BNSTpm). Few T-labelled cells were present outside these subdivisions. In the BNST, E2- and DHT-labelled neurons were present in all subdivisions, whereas $\mathrm{T}$ labelling was confined to the antero- and posteromedial subdivisions of BNST. These results suggest that the distribution of androgen- and estrogen receptor-containing neurons overlap considerably in nuclei which transmit chemosensory signals in the control of mating behavior.
\end{abstract}

\section{INTRODUCTION}

Mating in the male Syrian hamster requires chemosensory stimuli from the olfactory and vomeronasal systems and hormonal input from the gonads; copulatory behavior is abolished if either signal is interrupted ${ }^{24,48}$. The neural pathways by which olfactory and vomeronasal signals reach the medial preoptic area (MPOA) to control sexual behavior have been described in detail (see ref. 32, for review). Mating behavior is prevented by bilateral lesions at all levels of the pathways from the receptors to the MPOA itself. These lesions include deafferentation or removal of the main and accessory olfactory bulbs ${ }^{25,41}$, lateral olfactory tract transections ${ }^{5}$, lesions of the rostral portion of the medial amygdaloid nucleus (Me) ${ }^{17}$, combined transection of the stria terminalis and the ventral amygdalofugal pathway ${ }^{16}$, lesions of the bed nucleus of the strial terminalis (BNST) ${ }^{29}$, and small lesions in the posterior MPOA ${ }^{29}$.

In addition to the integrity of these chemosensory pathways, gonadal steroid hormones are also essential for male copulatory behavior. Mating behavior is prevented when circulating steroids are reduced in response to short-day photoperiod, or eliminated via castration $^{24}$. Replacement of testosterone (T) or its principle metabolites, estradiol (E2) or dihydrotestosterone (DHT), restores mating in castrate males ${ }^{10,20,27,40}$. It is presumed that this behavioral activation is dependent upon gonadal steroids acting through specific receptors in neurons of the limbic system, including olfactory and vomeronasal pathway nuclei.

In the hamster, Krieger et al..$^{15}$, and Doherty and Sheridan ${ }^{6}$ identified nuclei that contain steroid-accumulating cells. Those that mediate chemosensory stim-

Correspondence: R.I. Wood, Department of Anatomy and Cell Biology, Medical Sciences II Building, University of Michigan, Ann Arbor, MI 48109-0616, USA. Fax: (1)(313) 763-1166.

* Present address: Department of Biological Sciences, Rutgers University-Newark, 135 Smith Hall, 101 Warren Street, Newark, NJ 07012, USA. 
uli and also contain abundant steroid receptors include Me, BNST, and MPOA. Whether individual neurons that relay chemosensory information also possess steroid hormone receptors is not known. Recent studies from our laboratory have suggested that specific subdivisions within each of these 3 nuclei transmit chemosensory information in the control of mating behavior". However, we lack a similarly detailed understanding of the distribution of steroid hormone receptors within Me, BNST, and MPOA. In the present study, steroid autoradiography was used to determine the location of T-, E2-, and DHT-accumulating cells within Me, BNST, and MPOA in relation to the pathways mediating chemosensory information.

\section{MATERIALS AND METHODS}

\section{Animals}

Eighteen adult male hamsters (Mesocricetus auratus) weighing 90-112 g were purchased from Charles River Laboratories, They were housed in groups of 3-6 per cage under a long day photoperiod ( $14 \mathrm{~h}$ light/day). Food and water werc provided ad libitum. Four to 7 days before use, the males were castrated via a mid-scrotal incision under sodium pentobarbital anesthesia $(10 \mathrm{mg} / 100 \mathrm{~g}$ b.w.).

\section{Hormone treatment}

On the day of the experiment, males received tritiated steroid in $50 \%$ ethanol as two i.p. injections spaced one half hour apart. Two hours after the first injection. the animals were deeply anesthetized with sodium pentoharbital $(15 \mathrm{mg} / 100 \mathrm{~g} \mathrm{b.w.})$ and decapitated. The brains were removed quickly, frozen onto a cryostat chuck in powdered dry ice for $5 \mathrm{~min}$, and then transferred to liquid nitrogen $\left(-196^{\circ} \mathrm{C}\right)$, where they were stored until sectioning.

To visualize androgen concentrating neurons, 4 males each received a total of $250 \mu \mathrm{Ci}(500) \mathrm{ng})$ of $\left[1,2,6,7,16,17 .{ }^{3} \mathrm{H}(N)\right)$ lestosterone: ([ $\left.{ }^{3} \mathrm{H}\right] \mathrm{T}$; spec, act. $=141 \mathrm{Ci} / \mathrm{mmol}$; New England Nuclear Research Products, Boston, MA). In addition, because testosterone can be aromatized to estrogen, a second group of 4 males each received a total of $69 \mu \mathrm{Ci}(200 \mathrm{ng})$ of the non-aromatizable androgen, dihydrotestosterone $\left(\left[\left[^{3} \mathrm{H}\right] \mathrm{DHT} ; 5 \alpha\right.\right.$-dihydro $\left[1,2,4,5,6,7-{ }^{3} \mathrm{H}\right] \mathrm{tes}$ tosterone; spec. act. $=100 \mathrm{Ci} / \mathrm{mmol}$; Amersham Co., Arlington Heights, IL) to account for labelling of estrogen-concentrating neurons following $\left[{ }^{3} \mathrm{H}\right] \mathrm{T}$ injection. To visualize estrogen concentrating neurons directly, each of 4 males were injected with a total of 200 $\mu \mathrm{Ci}(340 \mathrm{ng})$ of $\left[2,4,6,7,16,17-{ }^{3} \mathrm{H}(N)\right]$ estradiol-17 $\beta\left(\left[{ }^{3} \mathrm{H}\right] \mathrm{E} 2\right.$; spec. act. $=160 \mathrm{Ci} / \mathrm{mmol}$; NEN).

For each group, two additional males served as controls. One male received 100-fold excess of non-radioactive hormone immediately before injection of tritiated steroid to determine specificity of labelling. The second male received only non-radioactive hormone to control for positive chemography, the artifactual reduction of silver grains due to emulsion handling or tissue processing.

\section{Tissuc processing}

Tissue was processed according to the methods of Pfaff and Keiner $^{20}$. Briefly, the brains were sectioned in a Lipshaw cryostat at $-18^{\circ} \mathrm{C}$ in the darkroom under a sodium vapor safelight. Six $-\mu \mathrm{m}$ sections were collected onto emulsion-coated slides (NTB-2, $n=6$; NTB-3. $n=12$; Eastman Kodak Co., Rochester, NY). A single section was saved each $100 \mu \mathrm{m}$; the adjacent section was collected onto a gel-subbed slide for Cresyl violet staining. Additional sections were collected for test slides to develop at intervais during the exposure perıod. Emulsion-dipped slides were stored with a dessicant in light-tight plastic slide. boxes inside light-sealed ammunition boxes at $4^{\circ} \mathrm{C}$ for $11-14$ months. They were developed in Kodak D-19 at $17^{\circ} \mathrm{C}$,

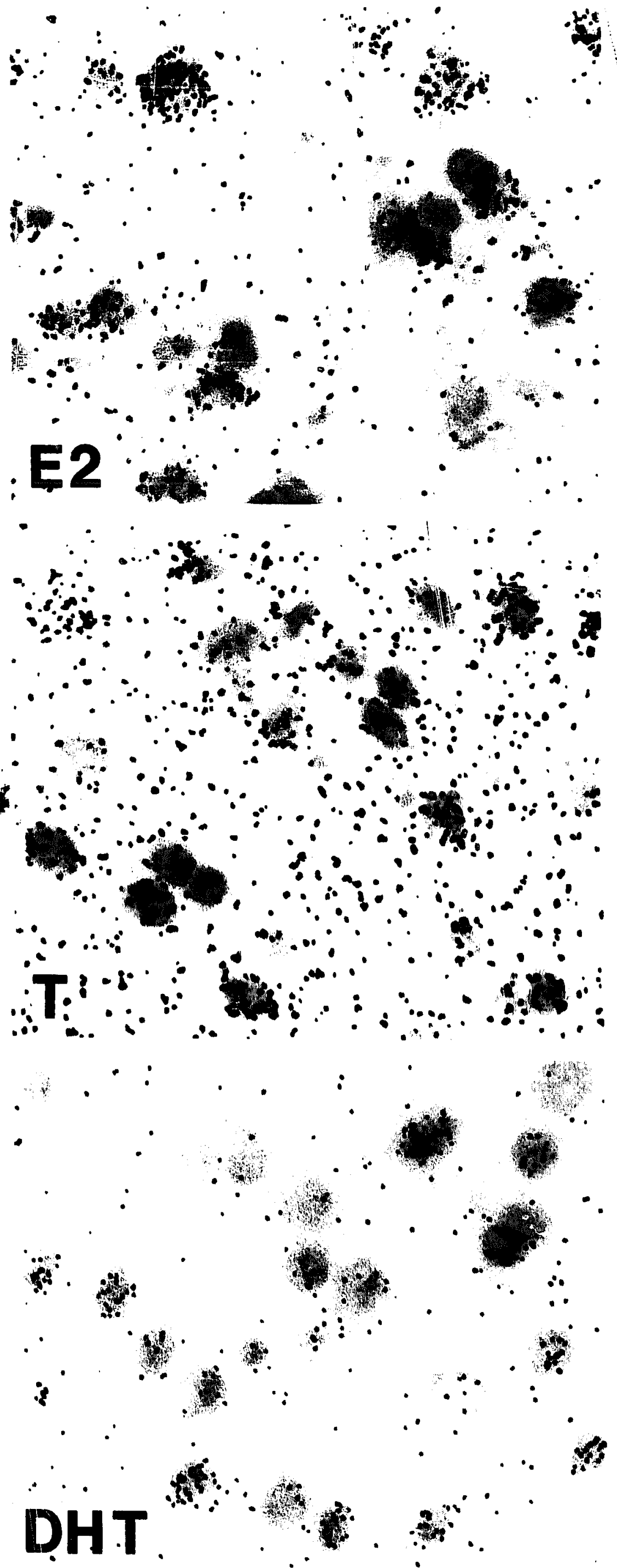

Fig. 1. Photomicrographs of representative heavily labelled neurons from male hamsters receiving systemic injections of $\left[{ }^{3} \mathrm{H}\right]$ estradiol (top), $\left[{ }^{3} \mathrm{H}\right]$ testosterone (middle), and $\left[{ }^{3} \mathrm{H}\right]$ dihydrotestosterone (bot(om). Note differences in intensity of labelling over the cell and amount of background label. 
washed, counter-stained with Cresyl violet, and coverslipped with Permount.

\section{Daia analysis}

A cell was considered labelled when the number of reduced silver grains over the stained cell body was equal to 3 or more times the background ${ }^{7}$. Background was determined by calculating the average number of silver grains over adjacent cell-sized areas of unstained neuropil. For each brain, steroid concentrating neurons within $\mathrm{Me}$, BNST, and MPOA were plotted onto standard sections of the hamster brain. For presentation of these data, a representative animal from each steroid treatment group was depicted.

\section{RESULTS}

\section{Labelling over individual neurons}

Labelled cells were present in the same forebrain regions previously described for the Syrian hamster by Doherty and Sheridan ${ }^{6}$ and Krieger et al. ${ }^{15}$. For the present study, detailed analysis of steroid receptor-con- taining cells was restricted to the amygdala, MPOA, and BNST. Fig. 1 presents photomicrographs of individual heavily labelled neurons from animals treated with estradiol (top), testosterone (middle), and DHT (bottom). Different exposure times were necessary to achieve substantial labelling of steroid-concentrating neurons; the mean exposure time averaged 11 months for E2, 14 months for $T$, and 15 months for DHT labelling. In hamsters treated with tritiated estradiol, there were abundant silver grains over individual neurons. DHT treatment resulted in relatively few grains per cell. Background labelling over cell-free areas was most noticeable in brains from animals treated with $\mathrm{T}$. Pretreatment with unlabelled ligand completely inhibited uptake of the ${ }^{3} \mathrm{H}$-lab slled steroid in hamsters injected with testosterone, DHT, or estradiol (data not shown).
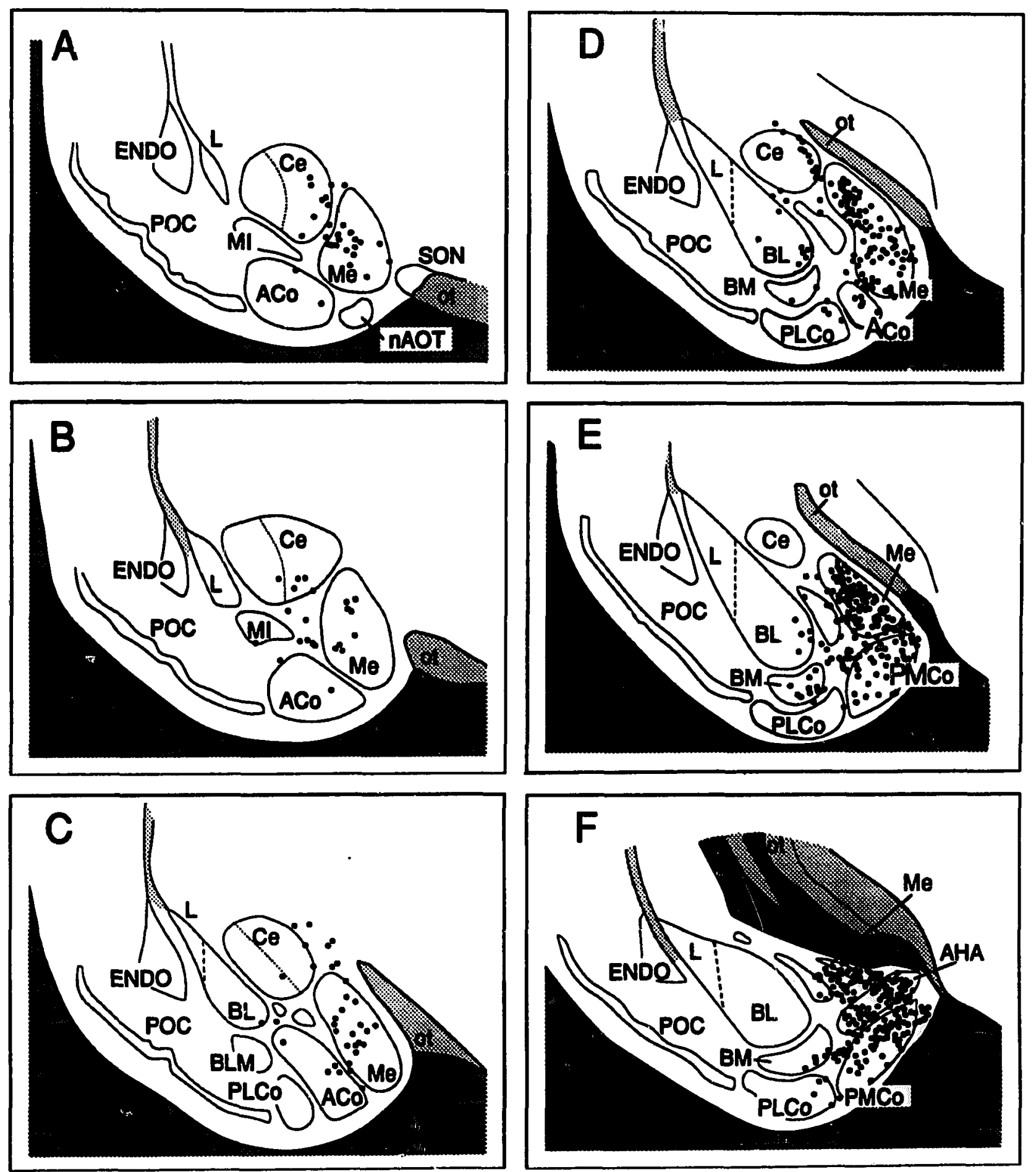

Fig. 2. The distribution of labelled neurons (dots) in drawings of coronal brain sections through the amygdala from a representative male hamster following systemic injection of $\left[{ }^{3} \mathrm{H}\right]$ estradiol. 


\section{Amygdala}

Figs. 2-4 illustrate the pattern of labelled neurons throughout the rostrocaudal extent of the amygdala in individual representative hamsters treated with tritiated estradiol (Fig. 2), testosterone (Fig. 3), and dihydrotestosterone (Fig. 4). In these figures, each dot represents a single labelled neuron, but because different exposure times werc necessary to achieve labelling, it is not possible to provide useful quantitative comparisons between the 3 hormone treatments. Neurons labelled with $\left[{ }^{3} \mathrm{H}\right]$ estrediol were found in all amygdaloid nuclei except the lateral nucleus (L) and nucleus of the accessory oliastory tract (nAOT), but they clustered in $\mathrm{Me}$, the posteromedial corticai niucleus (PMCo, Fig. 2E,F), and the amygdalohippocampal area (AHA, Fig. 2F). Within the medial nucleus, estrogen-concentrating neurons were present in both anterior and posterior subdivisions, with a prominent group of labelled cells in the posterndorsal region (Fig. 2E).
By contrast, testosterone treatment produced a more restricted pattern of labelled neurons in the amygdala (Fig. 3). Unlike the pattern of estradiol-labelled neurons, cells labelled by testosterone treatment were virtually absent from the posterolateral cortical nucleus (PLCo), the central nucleus (Ce), and the basolateral and basomedial nuclei (BL and BM). Testosteroneconcentrating neurons were abundant and heavily labelled in posterodorsal Me and AHA (Fig. 3E,F), but few labelled cells were present in the anterior portion of Me (Fig. 3A,B). Interestingly, DHT treatment (Fig. 4) produced more widespread labelling than did testosterone. Although the specific brain sections from the individual illustrated in Fig. 4 do not show labelling in all nuclei, in general, DHT-labelled neurons were present in the same amygdaloid nuclei labelled with tritiated estradiol. However, estradiol-concentrating neurons appeared to be more numerous. As with testosterone and estradiol treatment, DHT-labelled neurons
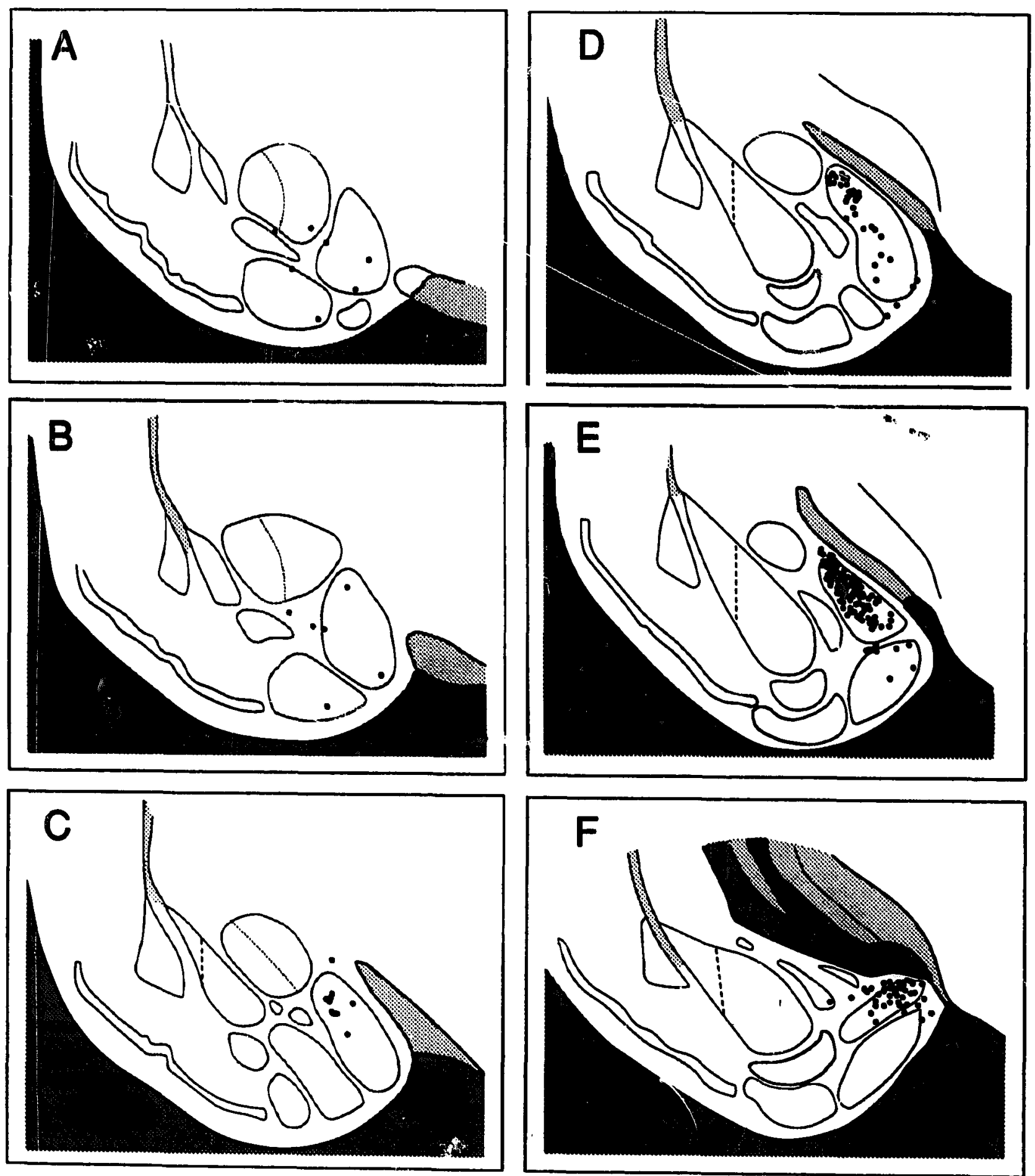

Fig. 3. The distribution of labelled neurons (dots) in drawings of coronal brain sections through the amygdala from a representative male hamster following systemic injection of $\left[{ }^{3} \mathrm{H}\right]$ testosterone. See Fig. 2 for identification of nuclear areas. 
were clustered in the posterodorsal Me and AHA (Fig. 4E,F).

\section{Bed nucleus of the stria terminalis and medial preoptic area}

Figs. 5-7 present the pattern of labelled neurons in the BNST and MPOA following treatment with $\left[{ }^{3} \mathrm{H}\right]$ estradiol (Fig. 5), testosterone (Fig. 6), and DHT (Fig. 7). The cytoarchitectural description of Maragos et al. ${ }^{21}$ is used here as a basis for the nuclei within the MPOA; that of Gomez and Newman ${ }^{11}$ is used for BNST. Estradiol treatment produced labelled neurons in the anteromedial and anterolateral BNST (BNSTam and BNSTal) at the rostral extent of this nucleus (Fig. 5A,B). At this, anci more caudal levels in the posteromedial BNST (BNSTpm), the most abundant labelling was confined medially; fewer labelled neurons were found in the posterointermediate BNST (BNSTpi) which extends from the posterior border of the body of the anterior commissure into the caudal part of the MPOA (Fig. 5C,D). Fig. 5E illustrates estradiol-concentrating cells in the preoptic BNST (pm and pi). In the MPOA, numerous heavily labelled cells were present throughout the MPN, and in the preoptic BNSTpm. Note, in particular, in Fig. 5C that the labelled neurons in BNSTpin form a continuum across the MPOA with those in the MPN. Labelled cells were also present in the anteroventral preoptic nucleus (AVPN) and median preoptic nucleus (MePO), but no labelling was observed in the magnocellular MPN (Fig. 5D) or suprachiasmatic nucleus (SCN; Fig. 5F).

As in the amygdala, labelled neurons in BNST and MPOA following tritiated testosterone injection were found in a subset of the areas that contained estradiol-concentrating neurons. Testosterone-labelled neurons were grouped closely together in the BNSTam, BSNTpm, and MPN, but were relatively sparse in the BNSTpi and subdivisions of the MPOA
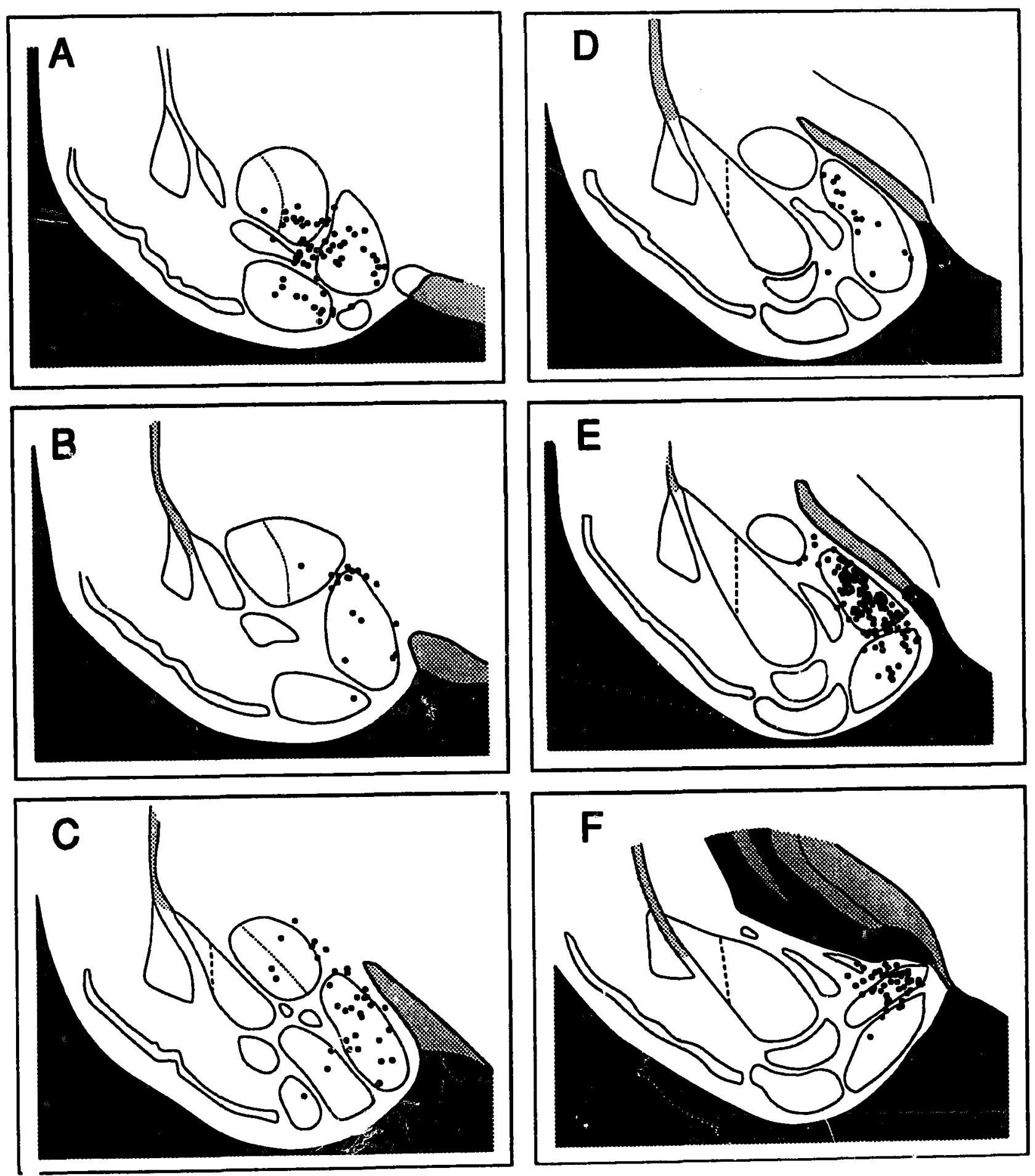

Fig. 4. The distribution of labelled neurons (dots) in drawings of coronal brain sections through the amygdala from a representative male hamster following systemic injection of $\left[{ }^{3} \mathrm{H}\right]$ dihydrotestosterone. See Fig. 2 for identification of nuclear areas. 

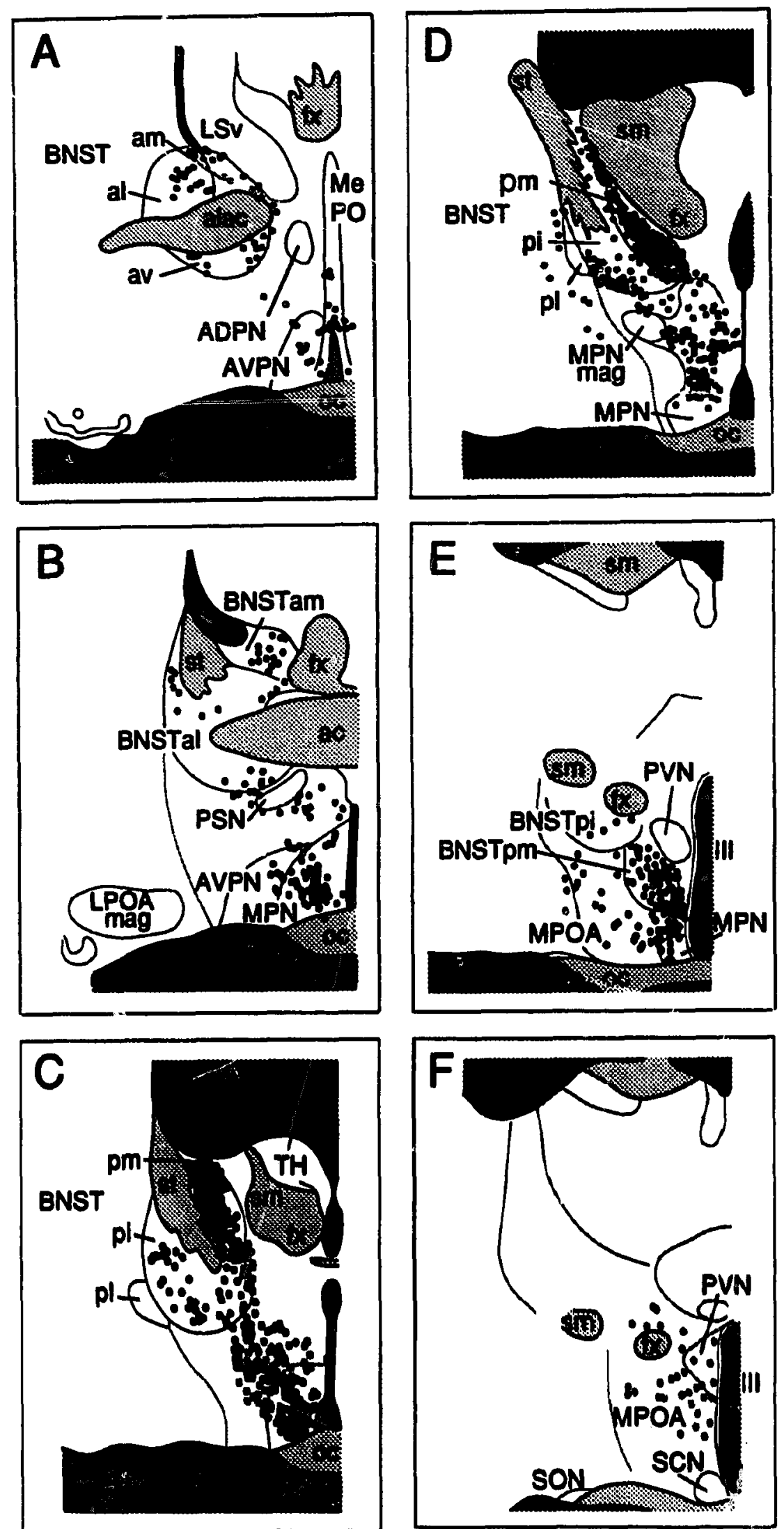

Fig. 5. The distribution of labelled neurons (dots) in drawings of coronal brain sections through the bed nucleus of the stria terminalis and the medial preoptic area from a representative male hamster following systemic injection of $\left[{ }^{3} \mathrm{H}\right]$ estradiol.

outside the MPN. The distribution of labelled neurons with $\left[{ }^{3} \mathrm{H}\right] \mathrm{DHT}$ was intermediate between that of $\left[{ }^{3} \mathrm{H}\right]$ estradiol and $\left[{ }^{3} \mathrm{H}\right]$ testosterone. DHT neurons were scattered throughout BNSTam, pm and pi, MPN, and in other regions of MPOA; few cells were present in BNSTal. With that exception, DHT labe!ling was found in the same subdivisions of BNST and MPOA that contained estrogen receptors.

\section{DISCUSSION}

The present study describes in detail the distribution of steroid receptor-containing neurons in 3 brain
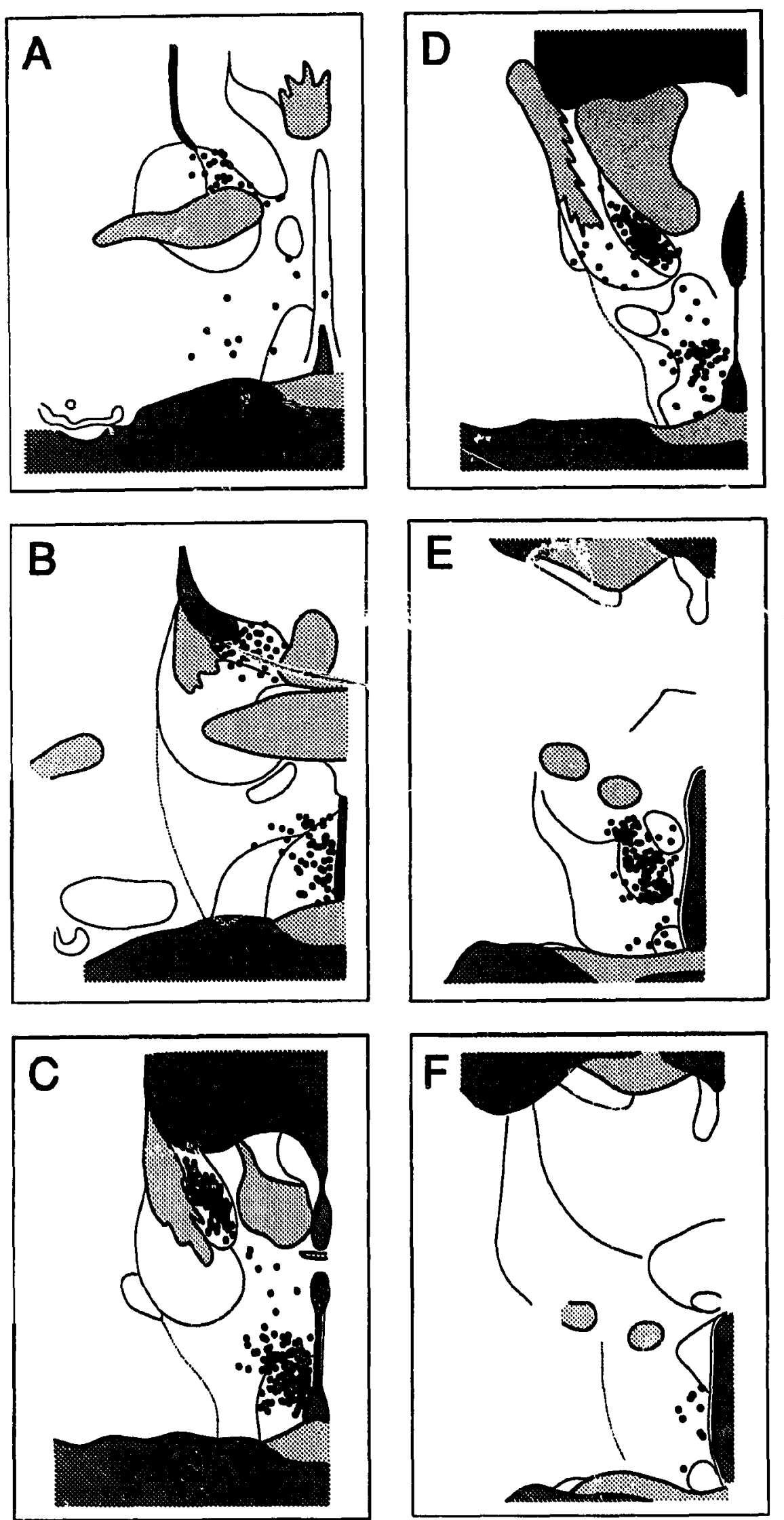

Fig. 6. The distribution of labelled neurons (dots) in drawings of coronal brain sections through the bed nucleus of the stria terminalis and the medial preoptic area from a representative male hamster following systemic injection of $\left[{ }^{3} \mathrm{H}\right]$ testosterone. See Fig. 5 for identification of nuclear areas.

nuclei important to the control of male sexual behavior: the MPOA, BNST, and Me. As determined using steroid autoradiography following injection of tritiated estradiol, testosterone, or the non-aromatizable androgen, dihydrotestosterone, neurons that contain androgen and estrogen receptors are widely distributed, but most abundant in specific subnuclear areas of the amygdala and preoptic area.

Previous studies using steroid autoradiography 4,33,36 and in situ hybridization ${ }^{38}$ have compared the location of androgen and estrogen receptors in rat, mouse, and 

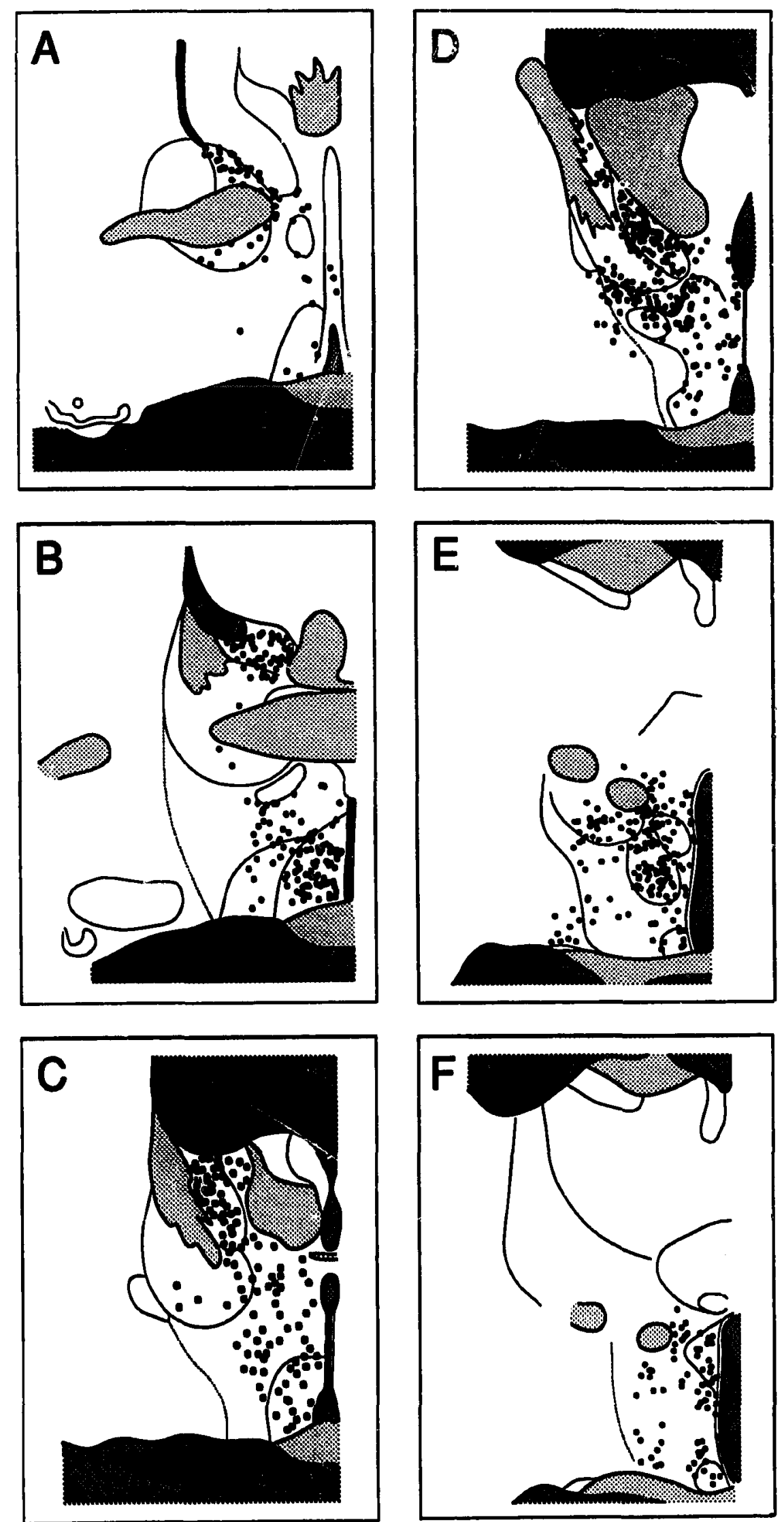

Fig. 7. The distribution of labelled neurons (dots) in drawings of coronal brain sections through the bed nucleus of the stria terminalis and the medial preoptic area from a representative male hamster following systemic injection of $\left[{ }^{3} \mathrm{H}\right]$ dihydrotestosterone. See Fig. 5 for identification of nuclear areas.

gerbil. These investigators have surveyed steroid receptors throughour the brain, and their findings are necessarily reported in less detail for any individual region. In general, androgen and estrogen receptors overlap considerably. Greater numbers of androgen receptorcontaining neurons have been described in lateral septum $^{4,33}$, thalamus ${ }^{36}$, hippocampus ${ }^{33,36,38}$, piriform cortex $^{36}$, brainstem nuclei ${ }^{4,38}$ and in the ventromedial nucleus of the hypothalamus ${ }^{33}$. Estrogen receptors may exceed androgen receptors only in the arcuate nucleus $^{4,33}$ and in the anterior olfactory nucleus, at least in gerbil brain ${ }^{4}$. With regard to the present study, MPOA, BNST, and Me in the hamster contain relatively large numbers of both gonadal steroid receptors ${ }^{6,15}$, but no differences between androgen and estrogen receptors have been described previously in these regions. Our goal was to provide a more detailed comparison of the locations of androgen and estrogen receptors within specific nuclei of a behaviorally relevant pathway whose function depends upon gonadal steroids.

In the present study, the distribution of estrogenconcentrating neurons overlapped considerably with that of androgen receptors, as determined with DHT autoradiography. It was not feasible in the present study to perform detailed quantitative analysis of the relative density of androgen- and estrogen-concentrating neurons because hamsters received different amounts of tritiated steroid, and the sections were exposed for varying lengths of time. This was necessary to ensure adequate labelling of neurons in hamsters from each group. Although confounding variables in the present study prevented quantitative comparisons between androgen and estrogen receptors, newly developed antibodies to the androgen and estrogen receptors $^{8,12,30,34,39}$ may permit such comparisons in the future. The absence of distinctly different nuclear distributions of androgen and estrogen receptors suggests that sexual behavior in the male is not uniquely sensitive to a single class of steroid hormones. This conclusion is supported by steroid replacement studies in castrate males. Both testosterone and its major metabolites are sufficient for the expression of copulatory behavior in the male hamster, as evidenced by mounting behavior in castrate males replaced centrally or peripherally with estradiol or $\mathrm{DHT}^{2,10,20,27,40}$. Although estradiol does not restore intromissions or ejaculations because peripheral tissues require androgenic stimulation, it appears that estrogens, like androgens, can act centrally to maintain major components of mating behavior ${ }^{20}$. Indeed, certain steroid receptorcontaining neurons may contain both androgen and estrogen receptors, as has been reported in the brain of the canary ${ }^{9}$. Therefore, we must consider that both androgen and estrogen receptors may be involved in the control of sexual behavior of the normal male hamster.

Although labelling with estradiol and DHT was present within the same brain regions, the restricted labelling of cells in Me, BNST, and MPOA following, $\left[{ }^{3} \mathrm{H}\right]$ testosterone treatment in this study was unexpected. If testosterone is bipotential, capable of metabolism into estradiol or DHT, it might be anticipated that cells labelled with $\left[{ }^{3} \mathrm{H}\right]$ testosterone would 
represent both androgen and estrogen receptor-containing neurons. According to this hypothesis, cells labelled by $\left[{ }^{3} \mathrm{H}\right]$ estradiol or $\left[{ }^{3} \mathrm{H}\right] \mathrm{DHT}$ would be a subset of those labelled with testosterone. In fact, in the present study, the testosterone-labelled cells were less widely distributed than those labelled with either estradiol or DHT. Differences in the amount or specific activity of labelled steroid administered cannot account for these results because testosterone-treated males received larger doses of steroid than males treated with estradiol or DHT.

This finding is difficult to interpret. Previous reports in the gerbil ${ }^{4}$ and rat $^{37}$ have described cells labelled with tritiated testosterone in the same areas as those labelled with tritiated estradiol and DHT. However, as noted above, these analyses did not deal with the subdivisions of the amygdaloid nuclei, the BNST, or the MPOA. Whether such labelling represents binding of testosterone directly to the androgen receptor or binding of testosterone's major metabolites cannot be determined using standard autoradiographic techniques. To address this question, Sheridan ${ }^{37}$ compared labelling of cells in female rats treated with $\alpha$ - and $\beta$-labelled testosterone. Whereas the $\alpha$-labelled androgen, similar to that used in the present study, retains the tritium label during metabolism, the tritium on $\beta$-labelled testosterone is lost during aromatization. In that study, binding of $\alpha$-labelled testosterone ressembled that in the present study, but the $\beta$-labelled androgen identified cells only in restricted regions of the BNSTpm and posterodorsal Me, areas that were the most heavily labelled with testosterone in the present study. Because labelling in the present study resembled that of Sheridan's $\alpha$-labelled testosterone, it seems likely that local aromatization of testosterone to estradiol contributes to some extent to labelling of cells during our testosterone autoradiography. Certainly, the potential exists for conversion of testosterone to estradiol or DHT. Steroid metabolic enzymes, aromatase and $5 \alpha$-reductase, are present in $\mathrm{Me}, \mathrm{BNST}$, and MPOA $^{13,22,31,35}$ as well as in peripheral tissues. It has not yet been determined in the hamster if aromatase and/or $5 \alpha$-reductase are found within steroid receptor-containing cells, although little colocalization of aromatase and estrogen receptors has been reported in the preoptic area of the Japanese quail ${ }^{1}$. Testosterone is also capable of binding directly to the androgen receptor, but at a much lower affinity than $\mathrm{DHT}^{3}$. Biochemical analyses of androgen metabolites following injection of tritiated testosterone suggest that testosterone is still the dominant steroid in circulation several hours after steroid treatment, although aromatization can produce significant quantities of estrogen in the preoptic area and amygdala ${ }^{14}$. The restricted pattern of testosterone labelling in the present study is cunsistent with low affinity testosterone binding to androgen receptors and limited metabolism to more readily bound steroids.

The distribution of steroid hormone receptors within Me, BNST, and MPOA is relevant to our understanding of how hormonal and chemosensory signals are integrated in the hamster brain. In the amygdala, steroid receptors are primarily restricted to the corticomedial division, and further, to nuclei within this division that receive input from the vomeronasal organ via the accessory olfactory bulb (AOB). These include Me and PMCo, as well as AHA, which receives AOB input indirectly from $\mathrm{PMCo}^{23}$. In addition, Me receives a linited projection from the main olfactory bulb (MOB), and indirect olfactory input through the anterior cortical and endopiriform nuclei. In turn, areas in BNST and MPOA that contain the largest numbers of steroid concentrating neurons are major targets of projections from Me and AHA. Together, these findings appear to support the hypothesis that chemosensory signals are relayed through hormone receptor-containing neurons for integration of these two determinants of male mating behavior.

However, comparison of the distribution of MOB and AOB terminals within the amygdala and the location of steroid hormone receptors suggests that neurons containing steroid receptors are not positioned to receive direct chemosensory input. In the medial amygdaloid nucleus, the majority of fibers from the AOB, and the only direct input from MOB, terminate in anterior $\mathrm{Me}^{18}$, whereas most hormone receptor cells are located in posterior Me. Anterior $\mathrm{Me}$ is essential for mating; electrolytic lesions of this region eliminate copulation $^{17}$. In contrasi, lesions of posterior Me only alter the temporal sequence of mating, suggesting that this region is not critical for the expression of the behavior ${ }^{19}$. In a similar manner, chemosensory information from anterior $\mathrm{Me}$ is transmitted to the more lateral regions of BNST (BNSTpi) and MPOA $^{11}$, whereas steroid receptor-containing neurons are concentrated medially in BNSTpm and MPN, areas receiving direct input from posterior Me. Steroid receptors in MPOA are important in the control of mating behavior because implants of androgen or estrogen directly into the MPOA restore mating in castrate males ${ }^{20}$. Similar studies have not been performed in Me.

Thus, based upon the location of steroid receptors within these 3 nuclei that relay chemosensory signals, there is little compelling evidence to suggest that substantial numbers of steroid-concentrating neurons 
themselves relay critical chemosensory information to brain regions controlling reproduction. There do exist connections between subnuclei that receive primarily chemosensory and hormonal input ${ }^{11}$, thus allowing for the indirect integration of these signals. Nonetheless chemosensory cues and steroid hormones, both of which are essential for mating behavior, are processed through distinct subdivisions of the same nuclei. Perhaps this is not surprising, because hormonal signals appear to serve a more permissive role, as evidence by the slow cessation of mating following castration ${ }^{24}$, whereas interruption of olfactory pathways abolishes mating immediately, suggesting that chemosensory signals acutely stimulate mating behavior ${ }^{25}$. It seems probable that integration of chemosensory and hormonal signals is achieved through communication between subnuclei of the mating behavior pathway.

Acknowledgements We are grateful to Robert L. Meisel, Sara S. Kollack and Steven E. Asmus for their critical evaluation of this manuscript. This work was supported by research and training grants from the NIH (NS-20629, HD-07514). Preliminary reports of this work were presented at the 21st Annual Meeting of the Society for Neuroscience, New Orleans, Louisiana, 1991.

\section{REFERENCES}

1 Balthazart, J., Foidart, A., Surlemont, C. and Harada, N., Neuroanatomical specificity in the co-localization of aromatase and estrogen receptors, J. Neurobiol., 22 (1991) 143-157.

2 Baum, M.J., Tobet, S.A., Starr, M.S. and Bradshaw, W.G., Implantation of dihydrotestosterone propionate into the lateral septum or medial amygdala facilitates copulation in castrated male rats given estradiol systemically, Horm. Behav., 16(1982) 208-223.

3 Coffey, D.S., Androgen action and the sex accessory tissues. In E. Knobil and J.D. Neill (Eds.), The Physiology of Reproduction, Raven, NY, 1988, pp. 1081-1119.

4 Commins, D. and Yahr, P., Autoradiographic localization of estrogen and androgen receptors in the sexually dimorphic area and other regions of the gerbil brain, J. Comp. Neurol., 231 (1985) 473-489.

5 Devor, M., Components of mating dissociated by lateral olfactory tract transections in male hamsters, Brain Res., 64 (1973) 437-441.

6 Doherty, P.C. and Sheridan, P.J., Uptake and retention of androgen in neurons in the brain of the golden hamster, Brain Res., 219 (1981) 327-334.

7 Farbach, S.E., Morrell, J.I. and Pfaff, D.W., Identification of medial preoptic area neurons that concentrate estradiol and project to the midbrain in the rat, J. Comp. Neurol., 247 (1986) 364-382.

8 Furlow, J.D., Ahrens, H., Mueller, G.C. and Gorski, J., Antisera to a synthetic peptide recognize native and denatured rat estrogen receptors, Endocrinology, 127 (1990) 1028-1032.

9 Gahr, M., Localization of androgen receptors and estrogen receptors in the same cells of the songbird brain, Proc. Natl. Acad. Sci. USA, 87 (1990) 9445-9448.

10 Gomez, D.M. and Newman, S.W., Medial nucleus of the amygdala in the Syrian hamster: a quantitative Golgi analysis of gonadal hormone regulation of neuronal morphology, Anat. Rec., 231 (1991) 498-509.

11 Gomez, D.M. and Newman, S.W., Differential projections of the anterior and posterior regions of the medial amygdaloid nucleus in the Syrian hamster, J. Comp. Neurol., 317 (1992) 195-218.
12 Greene, G.L., Sobel, N., King, W.J. and Jensen, E.V., Immunochemical studies of estrogen receptors, J. Steroid Biochem., 20 (1984) 51-56.

13 Hutchison, R.E., Hutchison, J.B., Steimer, T., Steel, E., Powers, J.B., Walker, A.P., Herbert, J. and Hastings, M.H., Brain aromatization of testosterone in the male Syrian hamster: effects of androgen and photoperiod, Neuroendocrinology, 53 (1991) 194203.

14 Krey, L.C., Ronchi, E. and Bittman, E.L., Effects of daylength on androgen metabolism and pulsatile luteinizing hormone secretion in male golden hamsters, Neuroendocrinology, 50 (1989) 533-545.

15 Krieger, M.S., Morrell, J.I. and Pfaff, D.W., Autoradiographic localization of estradiol-concentrating cells in the female hamster brain, Neuroendocrinology, 22 (1976) 193-205.

16 Lehman, M.N., Neural pathways of the vomeronasal and olfactory systems controlling sexual behavior in the male golden hamster, Dissertation, University of Michigan, 1982, 168 pp.

17 Lehman, M.N., Winans, S.S. and Powers, J.B., Medial nucleus of the amygdala mediates chemosensory control of male hamster sexual behavior, Science, 210 (1980) 557-560.

18 Lehman, M.N. and Winans, S.S., Vomeronasal and olfactory pathways to the amygdala controlling male hamster sexual behavior, Brain Res., 240 (1982) 27-41.

19 Lehman, M.N., Powers, J.B. and Winans, S.S., Stria terminalis lesions alter the temporal pattern of copulatory behavior in the male golden hamster, Behav. Brain Res., 8 (1983) 109-128.

20 Lisk, R.D. and Bezier, J.L., Intrahypothalamic hormone implantation and activation of sexual behavior in the male hamster, Neuroendocrinology, 30 (1980) 220-227.

21 Maragos, W.F., Newman, S.W., Lehman, M.N. and Powers, J.B., Neurons of origin and fiber trajectory of amygdalofugal projections to the medial preoptic area in Syrian hamsters, J. Comp. Neurol., 280 (1989) 59-71.

22 Martini, L., The $5 \alpha$-reduction of testosterone in the neuroendocrine structures. Biochemical and physiological implications. Endocr. Rev., 3 (1982) 1-25.

23 Meredith, M., The vomeronasal organ and accessory olfactory system in the hamster. In D. Muller-Schwarze and R.M. Silverstein, (Eds.), Chemical Signals: Vertebrates and Aquatic Invertebrates, Plenum, NY, 1980, pp. 303-326.

24 Morin, L. and Zucker, I., Photoperiodic regulation of copulatory behavior in the male hamster, J. Endocrinol., 77 (1978) 249-258.

25 Murphy, M.R. and Schneider, G.E., Olfactory bulb removal eliminates mating behavior in the male golden hamster, Science, 167 (1970) 302-304.

26 Pfaff, D. and Keiner, M., Atlas of estradiol-concentrating cells in the central nervous system of the female rat, J. Comp. Neurol., 151 (1973) 121-158.

27 Powers, J.B., Bergondy, M.L. and Matochik, J.A., Male hamster sociosexual behaviors: effects of testosterone and its metabolites, Physiol. Behav., 35 (1985) 607-616.

28 Powers, J.B., Fields, R.B. and Winans, S.S., Olfactory and vomeronasal system participation in male hamsters' attraction to female vaginal secretions, Physiol. Behav., 22 (1979) 77-84.

29 Powers, J.B., Newman, S.W. and Bergondy, M.L., MPOA and BNST lesions in male Syrian hamsters: differential effects on copulatory and chemoinvestigatory behaviors, Behav. Brain Res., 23 (1987) 181-195.

30 Prins, G.S., Birch, L. and Greene, G.L., Androgen receptor localization in different cell types of the adult rat prostate, Endocrinology, 129 (1991) 3187-3199.

31 Roselli, C.E., Horton, L.E. and Resko, J.A., Distribution and regulation of aromatase activity in the rat hypothalamus and limbic system, Endocrinology, 117 (1985) 2471-2477.

32 Sachs, B.D. and Meisel, R.L., The physiology of male sexual behavior. In E. Knobil and J.D. Neill (Eds.), The Physiology of Reproduction, Raven, NY, 1988, pp. 1393-1486.

33 Sar, M. and Stumpf, W.E., Autoradiographic localization of radioactivity in the rat brain after the injection of 1,2-3Htestosterone, Endocrinology, 92 (1973) 251-256.

34 Sar, M., Lubahn, D., French, F. and Wilson, E., Immunohisto- 
chemical localization of the andreogen receptor in rat and human tissues, Endocrinology; 127 (1990) 3180-3186.

35 Selmanoff, M.K., Brodkin, L.D., Weiner, R.I. and Siiteri, P.K., Aromatization and $5 \alpha$-reduction of androgens in discrete hypothalamic and limbic regions of the male and female rat, Endrcrinology, 101 (1977) 841-848.

36 Sheridan, P.J., Localization of androgen- and estrogen-concentrating neurons in the diecephalon and telencephalon of the mouse, Endocrinology; 103 (1978) 1328-1334.

37 Sheridan, P.J., The nucleus interstitialis striae terminalis and the nucleus amygdaloideus medialis: prime targets for androgen in the rat forebrain, Endocrinology, 104 (1979) 130-136.

38 Simerly, R.C., Chang. C., Muramatsu, M. and Swanson, L.W., Distribution of androgen and estrogen receptor mRNA-contain- ing cells in the rat brain: an in situ hybridization study, J. Comp. Neurol., 294 (1990) 76-95.

39 Takeda, H. and Chang, C., Immunohistochemical and in situ hybridization analysis of androgen receptor expression during development of the mouse prostate gland, J. Endocr., 129 (1991) 83-89.

40 Whalen, R.E. and DeBold, J.F., Comparative effectiveness of testosterone, androstenedione and dihydrotestosterone in maintaining mating behavior in the castrated male hamster, Endocrinology, 95 (1974) 1674-1679.

41 Winans, S.S. and Powers, J.B., Olfactory and vomeronasal deafferentation of male hamsters: histological and behavioral analyses, Brain Res., 126 (1977) 325-344. 